\title{
Enhanced intimal thickening of expanded polytetrafluoroethylene grafts coated with fibrin or fibrin-releasing vascular endothelial growth factor in the pig carotid artery interposition model
}

Beat H. Walpoth, MD, ${ }^{a}$ Prisca Zammaretti, PhD, ${ }^{\mathrm{b}, *}$ Mustafa Cikirikcioglu, MD, PhD, ${ }^{\mathrm{a}, *}$ Ebrahim Khabiri, MD, M. Karim Djebaili, MD, ${ }^{a}$ Jean-Claude Pache, MD, ${ }^{c}$ Jean-Christophe Tille, MD, PhD, ${ }^{c}$ Yacine Aggoun, $\mathrm{MD}^{\mathrm{d}}$ Denis Morel, MD, ${ }^{e}$ Afksendiyos Kalangos, MD, PhD, ${ }^{a}$ Jeffrey A. Hubbell, PhD, ${ }^{b, f}$ and Andreas H. Zisch, PhD ${ }^{b, g, h}$

From the Clinic of Cardiovascular Surgery, University of Geneva, ${ }^{\text {a }}$ Switzerland; Institute for Biomedical Engineering and Department of Materials Science, Swiss Federal Institute of Technology Zurich and University of Zurich, ${ }^{\mathrm{b}}$ Switzerland; Department of Clinical Pathology, University of Geneva, ${ }^{\mathrm{c}}$ Switzerland; Department of Anaesthesiology Research, University of Geneva, ${ }^{\mathrm{d}}$ Switzerland; Division of Pediatric Cardiology, University Hospital of Geneva, ${ }^{e}$ Switzerland; Institute of Bioengineering, Swiss Federal Institute of Technology, Lausanne, Switzerland; Department of Obstetrics, University Hospital of Zurich, Switzerland; and Center for Integrative Human Physiology of the University of Zurich, ${ }^{\mathrm{h}}$ Switzerland.

The study was supported by grants of the Swiss National Science Foundation and the Swiss Heart Foundation to B. H. W., the Gebert Ruef Foundation to A. H. Z. and J. A. H., and the European Union FP6project Heart Repair.

Received for publication May 31, 2006; revisions received Aug 24, 2006; accepted for publication Sept 19, 2006.

Address for reprints: Andreas Zisch, PhD, Department of Obstetrics, University Hospital Zurich, Frauenklinikstr. 10, $8091 \mathrm{Zu-}$ rich, Switzerland (E-mail: andreas.zisch@ usz.ch); Beat H. Walpoth, MD, Clinic of Cardiovascular Surgery, University Hospital Geneva, 1211 Geneva 14, Switzerland (E-mail: beat.walpoth@ @cuge.ch).

*Prisca Zammaretti and Mustafa Cikirikcioglu contributed equally to this article.

J Thorac Cardiovasc Surg 2007;133:1163-70 0022-5223/ $\$ 32.00$

Copyright () 2007 by The American Association for Thoracic Surgery

doi:10.1016/j.jtcvs.2007.01.029
Objective: Intimal hyperplasia and surface thrombogenicity are major factors in the high failure rate of synthetic small-diameter bypass grafts. Vascular endothelial growth factor is a potent stimulus for endothelial growth, and its provision in a fibrin matrix coating at the luminal graft surface may hold a key to spontaneous graft endothelialization and improved graft patency.

Methods: Pigs underwent bilateral carotid artery interposition of expanded polytetrafluoroethylene grafts either impregnated with fibrin $(n=11)$-engineered to

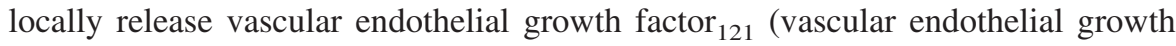
factor-fibrin; $\mathrm{n}=11)$ - or left uncoated $(\mathrm{n}=12)$. Graft patency was assessed by quantitative carotid angiography followed by graft histomorphometry at the 1-month experimental end point.

Results: Patency rates were not significantly different between study groups. Grafts coated with fibrin or vascular endothelial growth factor-fibrin exhibited significantly increased angiographic narrowing at the proximal anastomosis (for both $P<$ .05 vs uncoated) and no difference at the distal anastomosis and the grafts' middle. Histological analysis showed $80 \%$ to $90 \%$ endothelial coverage and buildup of intima throughout the lengths of all grafts. Examination of the grafts' midportion revealed significantly enlarged neointimal layers of smooth muscle actin-positive cells in grafts coated with vascular endothelial growth factor-fibrin $(242 \pm 47$ $\left.\mu \mathrm{m}^{2} / \mu\right)$ and fibrin $\left(177 \pm 41 \mu \mathrm{m}^{2} / \mu\right)$, compared with uncoated grafts $(131 \pm 39$ $\mu \mathrm{m}^{2} / \mu$ ) (for both $P<.05$ vs uncoated). This thickening could not be explained by enhanced inflammation or vessel wall angiogenesis, which were minimal at the experimental end point.

Conclusions: Fibrin and vascular endothelial growth factor produced effects deleterious to graft healing, by increasing the narrowing at proximal anastomosis and neointimal growth beyond that seen in uncoated grafts. It may reflect direct activation by exogenous vascular endothelial growth factor of vascular smooth muscle cells.

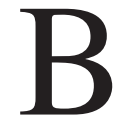
ypass surgery is a common treatment for ischemic heart or limb disease, but many patients requiring arterial replacements lack suitable autologous small-diameter vein and/or arterial grafts for bypass surgery. Synthetic grafts can be substituted for diseased arteries and function well as long as they are of sufficiently large diameter and there exists high blood flow. In low-flow conditions they are prone to thrombosis. ${ }^{1}$ The application of porous expanded polytetrafluoroethylene (ePTFE) grafts, particularly at longer length and small internal diameters $(<6 \mathrm{~mm})$, is frequently associated with early thrombosis and late intimal 

Abbreviations and Acronyms
ePTFE = expanded polytetrafluoroethylene
SEM = scanning electron microscopy
TBS $=$ tris-buffered saline
VEGF $=$ vascular endothelial growth factor

hyperplasia, leading to a high occlusion rate. Overall, ePTFE grafts exhibit inferior patency when compared with autologous vein/artery grafts used as arterial substitutes. ${ }^{2}$

One difference between artery/vein grafts and prosthetic grafts is the confluent endothelial lining, which is the only nonthrombogenic blood-compatible surface and which plays an active role in maintaining vessel patency. The ideal synthetic blood vessel implant would therefore support the growth of functional endothelium lining an organized neointima with its resistance to thrombosis and protection from exuberant neointima formation. Clinical in vitro endothelialization of ePTFE grafts with mass-cultured autologous endothelial cells before implantation confirmed the expectation that a confluent endothelium could prevent thrombogenic complications at the blood-material interface and distinctly improve graft performance; indeed, clinical studies have demonstrated that such grafts can function as well as autologous vein grafts. ${ }^{3}$ However, this procedure is tedious and costly, and may be technically limited to practice in speciality clinics. Ongoing research has therefore turned toward development of spontaneously endothelializing synthetic vessel implants ${ }^{4-6}$ by active recruitment of endothelial cells across the anastomoses from the native vessel, transmural ingrowth of capillaries, or recruitment of circulating endothelial progenitor cells. Surface treatments to increase endothelial cell adherence and retention on ePTFE grafts include deposition of cell adhesion proteins (eg, collagen, ${ }^{7}$ laminin, ${ }^{8}$ and complex cell-derived extracellular matri$\left.\operatorname{ces}^{4,9}\right)$. Surface coatings have also been considered to deliver angiogenic substances such as vascular endothelial growth factor (VEGF) ${ }^{10,11}$ or fibroblast growth factor(s) ${ }^{6}$ with the idea to accelerate endothelialization while inhibiting neointimal hyperplasia.

We recently introduced a scheme of covalent affixation of VEGF in fibrin matrix that protects VEGF from washout by flow. ${ }^{12,13}$ For that, we created a genetically engineered recombinant variant of $\mathrm{VEGF}_{121}, \alpha_{2} \mathrm{PI}_{1-8}-\mathrm{VEGF}_{121}$, that becomes crosslinked to fibrin during fibrin coagulation through the transglutaminase activity of factor XIII. The fibrin-bound $\alpha_{2} \mathrm{PI}_{1-8}-\mathrm{VEGF}_{121}$ can only be liberated by cellsecreted proteases, such as plasmin or matrix metalloproteinases, produced at the surface of cells that contact or invade the fibrin matrix. ${ }^{14}$ In the present study, the unique VEGF retention-and-release property of such engineered fibrin matrix coating was tested for spontaneous endothelial coverage of surfaces of synthetic 4-mm ePTFE bypass grafts that were interposed in pig carotid arteries.

\section{Materials and Methods Graft Coating}

Standard ePTFE grafts of 4-mm internal diameter with a through porosity and an internodal distance of $30 \mu \mathrm{m}$ (provided by Dr P. Martakos, Atrium Medical Corporation, Hudson, $\mathrm{NH}$ ) were cut to $7 \mathrm{~cm}$ lengths and freshly impregnated with fibrin under sterile laminar flow conditions, typically approximately 24 hours before surgery (Figure 1, A). The components used to form fibrin matrix with covalently affixed VEGF $_{121}$ have been described. ${ }^{12-14}$ Before coating, the grafts were placed into centrifuge tubes and immersed in pure ethanol. To achieve complete wetting, all air was removed from the grafts by applying vacuum with a membrane vacuum pump. Grafts were then immersed for 15 minutes under vacuum in tris-buffered saline (TBS) to remove residual ethanol and then in TBS containing 2 National Institutes of Health units $/ \mathrm{mL}$ of human thrombin (Sigma, St Louis, Mo) and $2.5 \mathrm{mmol} / \mathrm{L} \mathrm{CaCl}_{2}$. To form the fibrin coating at the graft flow surface, $0.5 \mathrm{~mL}$ of TBS containing 10 $\mathrm{mg} / \mathrm{mL}$ human fibrinogen (plasminogen-free quality; Sigma) and 2 $\mathrm{U} / \mathrm{mL}$ factor XIII (provided by Baxter BioScienceAG, Vienna, Austria) were injected with a $1-\mathrm{mL}$ syringe through the thrombin-impregnated ePTFE. VEGF-containing fibrin coatings were formed by admixture of $0.5 \mu \mathrm{g} / \mathrm{mL} \alpha_{2} \mathrm{PI}_{1-8}-\mathrm{VEGF}_{121}$ to the solution of fibrinogen and factor XIII. Immediately after fibrin polymerization, the ePTFE tubes were flushed with sterile TBS and kept in TBS at $4^{\circ} \mathrm{C}$ until implantation.

\section{Arteriovenous Shunt Perfusion System}

Stability of the fibrin coating on ePTFE grafts under flow and acute thrombogenicity were assessed in a porcine femorofemoral arteriovenous extracorporeal circuit as described previously. ${ }^{15}$ Perfusion was performed for 30 minutes. A series of shunts was constructed by connecting $5 \mathrm{~cm}$ graft segments through metallic spacers. Each series of shunts consisted of fibrin, VEGF-fibrin, and bare control grafts randomly positioned along the shunt $(n=4$ for each group). As evaluation, confocal microscopy with Oregon green fluorescent fibrin staining (stability test of coating) and scanning electron microscopy (SEM) (thrombogenicity and cell deposition test) were used.

\section{Surgical Pig Carotid Artery Replacement}

The experimental protocol was approved by the Ethical Animal Committee of the University of Geneva and the Governmental Veterinary office of the State of Geneva (No. 31.1.1081/2139/II) and conducted in compliance with the "Guide for the Care and Use of the Laboratory Animals" (National Research Council, Washington, DC: National Academy Press; 1996). Seventeen Swiss house swine aged 3 to 4 months $(29 \pm 2 \mathrm{~kg})$ were used in this study. They were fasted the night before surgery and received normal food throughout the postoperative period. Bilateral carotid artery graft interposition was performed through a cervical midline incision. The carotid arteries were prepared and freed on a length of approximately 8 to $10 \mathrm{~cm}$ by taking care to prevent vascular spasm with externally applied papaverine solution. After proximal and distal clamping of the carotid artery, a segment of approximately $3 \mathrm{~cm}$ was excised in a beveled way. The prostheses were 
A
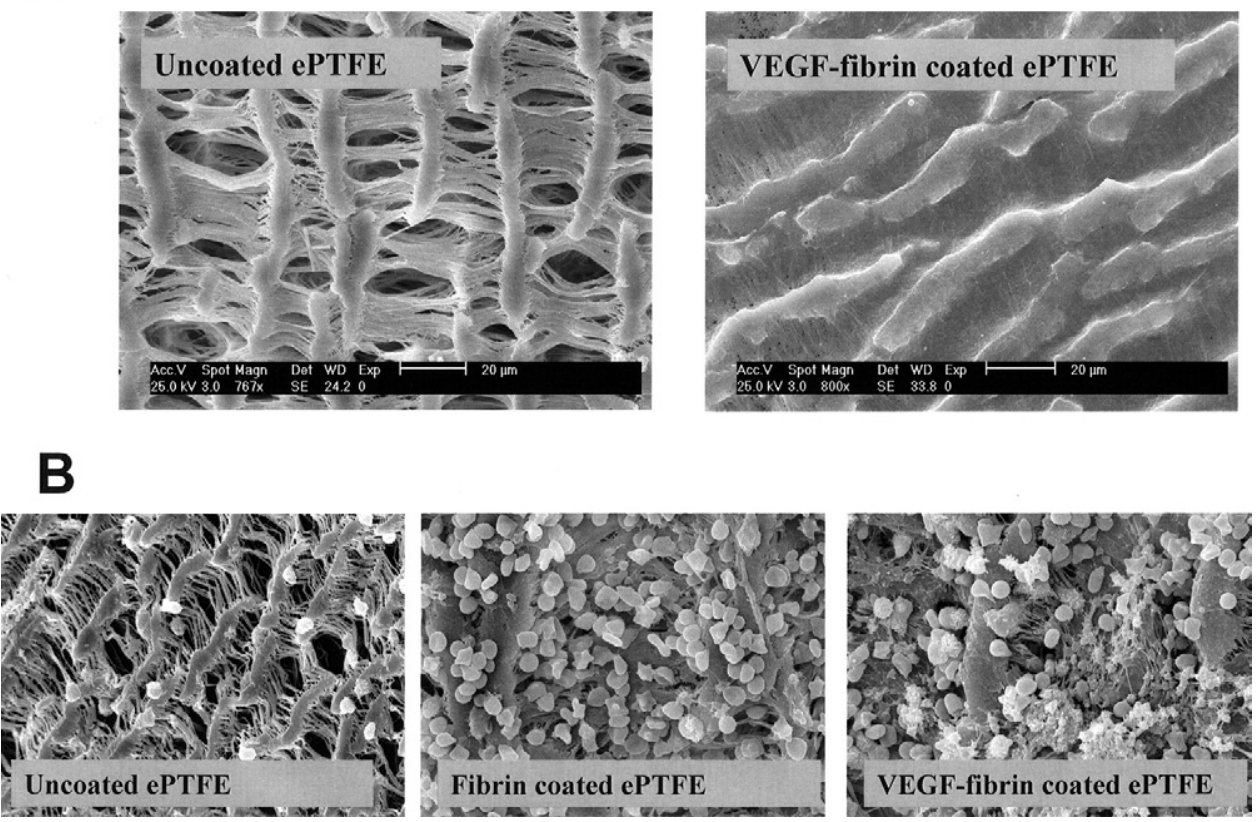

Figure 1. A, Scanning electron micrographs of noncoated and VEGF-fibrin-coated ePTFE surface before arteriovenous shunt blood perfusion. $B$, SEM shows increased platelet deposition and microthrombus formation on fibrin and VEGF-fibrin-coated ePTFE surfaces compared with noncoated grafts after $\mathbf{3 0}$ minutes of extracorporeal arteriovenous shunt perfusion.

also beveled and trimmed to a length of $5 \mathrm{~cm}$. Proximal and distal anastomoses were performed with 7-0 polypropylene continuous suture. The quality of surgery was evaluated with intraoperative transit time flow measurement and immediate postoperative selective carotid angiography that was quantified according to the modified North American Symptomatic Carotid Endarterectomy Trial formula. ${ }^{16}$ Throughout the survival period, animals were fed $0.5 \mathrm{~g}$ of aspirin daily until sacrifice at 1 month. After 1 week, duplex examination was performed in a mask narcosis (isoflurane 4\%) after standard premedication. At the 1-month study end point, a control selective carotid angiography was first performed fol- lowed by exposure of the grafts. After 10,000 units of intravenous heparin, grafts were excised with $2 \mathrm{~cm}$ of native proximal and distal carotid artery. They were then rinsed with saline followed by $4 \%$ formaldehyde for fixation.

\section{Immunohistochemistry and Scanning Electron Microscopy}

Formalin-fixed vessel graft explants were cut in half, opened longitudinally, and separated into 2 halves, 1 for SEM analysis and 1 embedded in paraffin for histomorphometry. Stainings were performed on deparaffinized sections with hematoxylin-eosin and

TABLE 1. Patency and stenosis rates (\%) at proximal/distal anastomoses and at the middle of the graft after one-month follow-up

\begin{tabular}{|c|c|c|c|c|}
\hline & \multirow[b]{2}{*}{ Patency } & \multicolumn{3}{|c|}{ Stenosis (\%) } \\
\hline & & Proximal anastomosis & Midgraft & Distal anastomosis \\
\hline Uncoated $(n=10)$ & $7 / 10$ & $36 \pm 3$ & $25 \pm 6$ & $35 \pm 5$ \\
\hline Fibrin coated $(\mathrm{n}=9)$ & $7 / 9$ & $51 \pm 4$ & $19 \pm 10$ & $39 \pm 9$ \\
\hline VEGF-fibrin coated $(n=9)$ & $7 / 9$ & $49 \pm 4$ & $25 \pm 9$ & $41 \pm 6$ \\
\hline Variance analysis* & 0.996 & 0.034 & 0.523 & 0.798 \\
\hline \multirow[t]{3}{*}{ Mann-Whitney $U$ test } & & $\mathbf{0 . 0 0 8}$ (uncoated vs fibrin) & & \\
\hline & & $\mathbf{0 . 0 0 8}$ (uncoated vs VEGF) & & \\
\hline & & 0.132 (fibrin vs VEGF) & & \\
\hline
\end{tabular}

Numbers in bold represent significant differences at the level of $P<0.05 . V E G F$, Vascular endothelial growth factor. *Chi-square test for nonmatched, parametric values, and Kruskal-Wallis test for nonmatched, nonparametric values. 
A
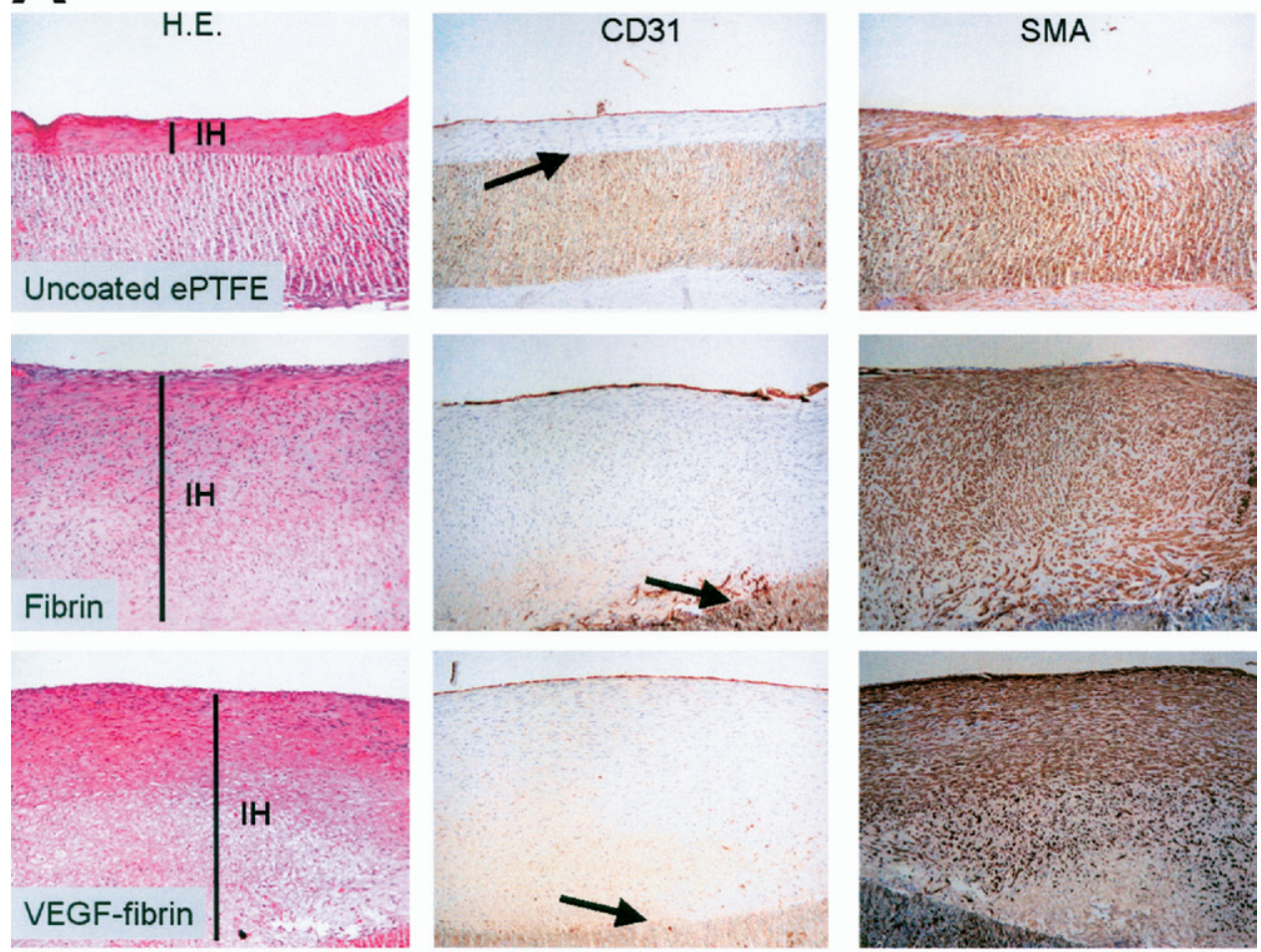

B
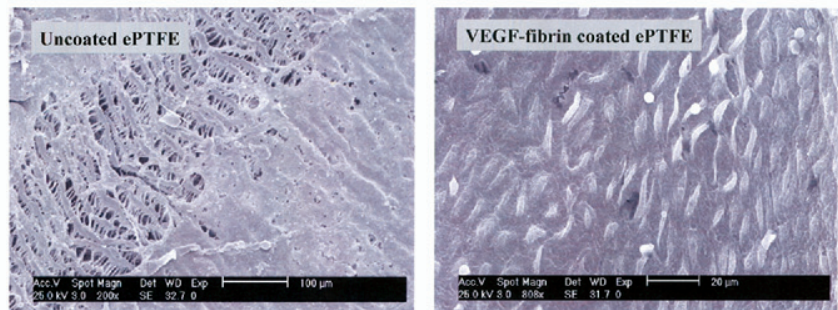

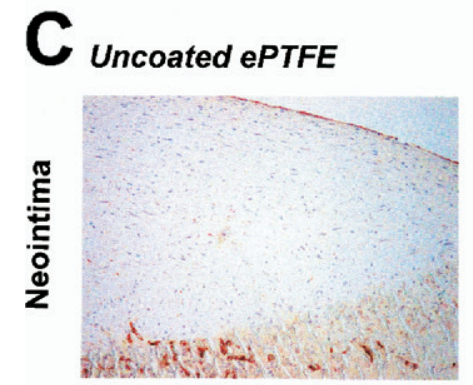

Fibrin coated ePTFE
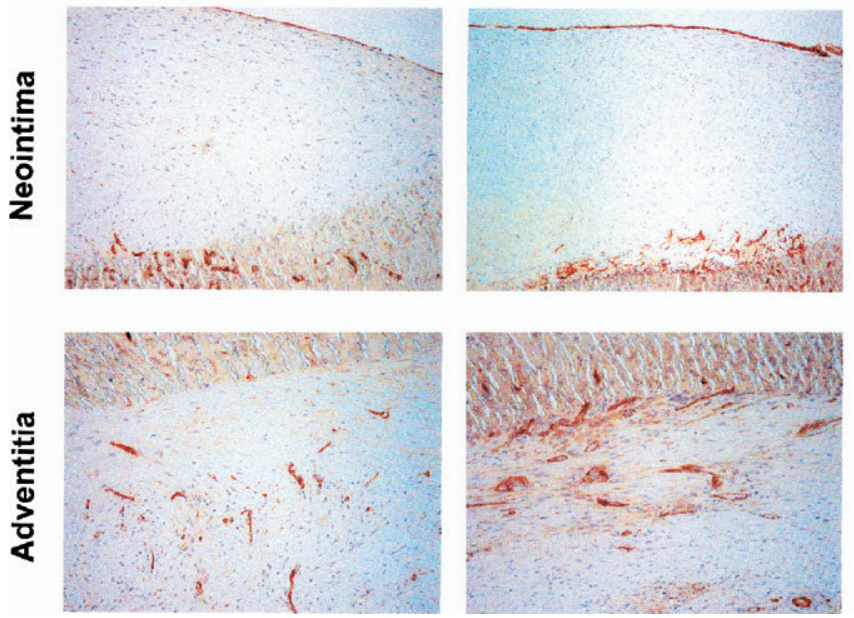
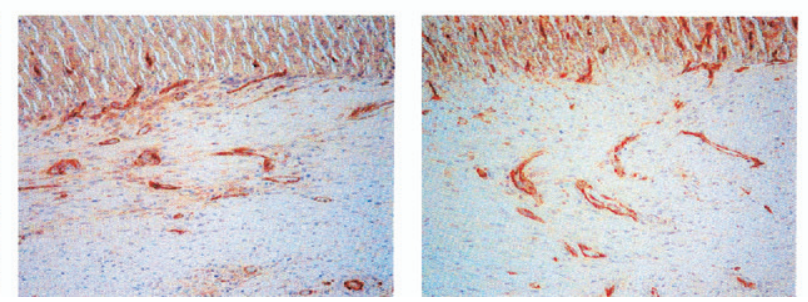
the following antibodies: goat polyclonal anti-CD31 (PECAM; Santa Cruz sc-1506) for endothelial cells; mouse antihuman smooth muscle actin (DAKO clone 1A4) for smooth muscle actinpositive cells; and MAC387 mouse anti-human macrophage L1 calprotectin (DAKO, M0747) for macrophage. Conventional pathology stains were performed with Miller for elastin and Landrum for fibrin.

\section{Histomorphometry}

Intimal hyperplasia and endothelial coverage were determined using a Leitz Medilux (Leica, Nussloch, Germany) motorized microscope, a Sony 3CCD color video camera DCC9-930P, and the software Leica Q-Win standard version Y2.3 for image analysis. The intimal area was defined as the region between luminal endothelium and ePTFE graft surface and calculated per unit length (micrometer squared/micrometer). The percentage of luminal graft surface neoendothelialization was expressed as the percentage of the total graft length. Neointimal and adventitial neoangiogenesis in the neointima was quantified by counting the numbers of CD31-positive vessels. Macrophage numbers in the neointima were obtained by counting MAC387-positive cells. Vessel and macrophage counts are expressed as numbers per high power field $(\times 400)$ with $n=10$ per graft sample. The inner surface morphology of the graft was examined by SEM (Philips XL20 SEM, Eindhoven, The Netherlands) at predefined locations, settings, and magnifications $(\times 20, \times 200$, and $\times 800$ magnification).

\section{Statistics}

The results are expressed as mean values \pm standard error of the mean. The Kruskal-Wallis test was used for variance analysis of nonmatched, nonparametric values between 3 groups. Thereafter, each group was compared with others using the Mann-Whitney $U$ test. Chi-square test was used to compare nonmatched, parametric values (Statistical Package for the Social Sciences version 11.5; SPSS Inc, Chicago, Ill).

\section{Results}

Fibrin Coating Is Stable and Prone to Early Cell Deposition

After 30 minutes of blood perfusion (arteriovenous shunt), the Oregon green fibrin staining by confocal microscopy was unchanged compared with unperfused grafts. Qualitative examination of coated (fibrin, VEGF-fibrin) and bare ePTFE grafts by SEM showed increased cellular deposition and microthrombus formation after arteriovenous shunt perfusion (Figure 1, B). None of the shunted grafts occluded during the procedure.

\section{Animal Follow-up After Surgery}

Seventeen pigs underwent bilateral carotid artery replacement with ePTFE grafts coated with fibrin $(n=11)$, VEGFfibrin $(\mathrm{n}=11)$, or left uncoated $(\mathrm{n}=12)$. Coated and uncoated ePTFE grafts had the same surgical handling characteristics. Three animals developed postimplantation complications and were removed from the study. One animal had to be sacrificed on postoperative day 3 because of stridor and respiratory complications; autopsy showed both grafts to be patent. One animal developed hind-limb ischemia after femoral artery occlusion secondary to angiographic catheter introduction and was sacrificed on postoperative day 10; both grafts were angiographically patent. One pig was sacrificed on postoperative day 7 after angiographic assessment of bilateral carotid artery occlusion associated with severe arteritis as assessed by histology.

\section{Assessment of Early and Late Graft Patency}

Twenty-eight ePTFE implants, 9 coated with fibrin, 9 coated with VEGF-fibrin, and 10 left uncoated, were analyzed for early and late graft patency. Intraoperative and immediately postoperative assessment of the surgical quality with transit time blood flow measurements and quantitative carotid angiography showed adequate graft perfusion and similar flow values in all 3 experimental groups and no significant differences in the extent of surgery-induced narrowing at the proximal and distal anastomoses. One-week follow-up by duplex measurement showed 3 of the 28 grafts, 1 in each study group, occluded; the 1-month follow up showed 2 additional graft occlusions in the uncoated study group and 1 additional graft occlusion in the fibrin and VEGF-fibrin study groups. Table 1 illustrates the quantitative angiography data at 1 month; 21 of 28 grafts, 7 in each study group, remained patent. Fibrin- and VEGF-fibrincoated ePTFE grafts showed significantly increased narrowing at the proximal anastomosis, namely, 51\% $\pm 4 \%$ and $49 \% \pm 4 \%$ (for both $P<.05$ vs uncoated) compared with

Figure 2. A, Graft histology at the experimental end point, 1 month, shows an increase of neointima formation on ePTFE grafts coated with fibrin or VEGF-fibrin over noncoated ePTFE. The pictures are taken from the grafts' middle portions. Immunohistochemistry with anti-CD31 for endothelial cells (middle), anti-smooth muscle actin for smooth muscle cells (right), and hematoxylin-eosin (left). The graft-neointimal border (arrows). B, Examination of graft surface ultrastructure at the experimental end point by SEM showed most parts lined by densely grown endothelial cells aligned in direction of flow. Sites of bare ePTFE surface were occasionally observed in noncoated grafts (left). VEGF-fibrin-coated graft with a confluent layer of aligned endothelial cells (right). C, Representative photomicrographs of CD31-stained neointima (upper row) and adventitia (lower row). There were no significant differences in capillary counts among uncoated, fibrin-coated, or VEGF-fibrin-coated grafts (see Table 3). In every study group, capillary formation was substantially higher in adventitia than in neointima. IH, intimal hyperplasia. 
TABLE 2. Morphometric analysis of intimal hyperplasia and neo-endothelial coverage of coated and noncoated expanded polytetrafluoroethylene grafts

\begin{tabular}{|c|c|c|c|c|c|}
\hline & $\begin{array}{l}\text { Uncoated } \\
(\mathrm{n}=7)\end{array}$ & Fibrin $(n=7)$ & $\begin{array}{l}\text { VEGF-fibrin } \\
(\mathrm{n}=7)\end{array}$ & $\begin{array}{l}\text { Kruskal-Wallis } \\
\text { test }\end{array}$ & Mann-Whitney $U$ test \\
\hline \multicolumn{6}{|l|}{ Intimal hyperplasia $\left(\mu \mathrm{m}^{2} /(\mu)\right.$} \\
\hline Whole graft & $167 \pm 35$ & $210 \pm 31$ & $267 \pm 39$ & 0.031 & $\begin{array}{l}0.132 \text { (uncoated vs fibrin) } \\
\mathbf{0 . 0 0 8} \text { (uncoated vs VEGF) } \\
0.307 \text { (fibrin vs VEGF) }\end{array}$ \\
\hline Anastomoses (proximal + distal) & $241 \pm 36$ & $356 \pm 47$ & $358 \pm 34$ & 0.026 & $\begin{array}{l}0.060 \text { (uncoated vs fibrin) } \\
\mathbf{0 . 0 0 8} \text { (uncoated vs VEGF) } \\
0.917 \text { (fibrin vs VEGF) }\end{array}$ \\
\hline Midgraft & $131 \pm 39$ & $177 \pm 41$ & $242 \pm 47$ & 0.007 & $\begin{array}{l}0.012 \text { (uncoated vs fibrin) } \\
\mathbf{0 . 0 0 5} \text { (uncoated vs VEGF) } \\
0.565 \text { (fibrin vs VEGF) }\end{array}$ \\
\hline \multicolumn{6}{|l|}{ Neo-endotelial coverage $(\%)$} \\
\hline Whole graft & $80 \pm 4$ & $82 \pm 3$ & $90 \pm 3$ & 0.172 & $\begin{array}{l}0.911 \text { (uncoated vs fibrin) } \\
0.152 \text { (uncoated vs VEGF) } \\
0.071 \text { (fibrin vs VEGF) }\end{array}$ \\
\hline Anastomoses (proximal + distal) & $91 \pm 3$ & $91 \pm 3$ & $94 \pm 2$ & 0.764 & $\begin{array}{l}0.728 \text { (uncoated vs fibrin) } \\
0.458 \text { (uncoated vs VEGF) } \\
0.764 \text { (fibrin vs VEGF) }\end{array}$ \\
\hline Midgraft & $75 \pm 5$ & $83 \pm 4$ & $89 \pm 3$ & 0.254 & $\begin{array}{l}0.451 \text { (uncoated vs fibrin) } \\
0.109 \text { (uncoated vs VEGF) } \\
0.346 \text { (fibrin vs VEGF) }\end{array}$ \\
\hline
\end{tabular}

VEGF, Vascular endothelial growth factor. Values are given as mean \pm standard error.

uncoated $(36 \% \pm 3 \%)$, and no difference at the distal anastomosis and the grafts' middle.

\section{Fibrin and Vascular Endothelial Growth Factor Increase Neointimal Thickening}

Gross histology at the 1-month experimental end point showed neointimal thickening related to surgical trauma and local inflammatory response at the grafts' proximal and distal anastomosis sites. Hematoxylin-eosin staining showed buildup of neointima along the entire luminal surface of ePTFE grafts. Landrum staining for fibrin remnants was negative, indicating complete remodeling of fibrin matrix into new tissue (not shown). In both coated and uncoated conditions, the size of neointima decreased toward the grafts' midregions. Grafts modified by fibrin and VEGF-fibrin elicited a significantly enlarged smooth muscle actin-positive neointimal layer compared with uncoated grafts in the following order: VEGFfibrin $>$ fibrin $>$ uncoated (Figure 2; Table 2). Histomorpho- metric evaluation of the intimal area by computer-assisted planimetry determined $242 \pm 47 \mu \mathrm{m}^{2} / \mu$ for VEGF-fibrincoated grafts (significant vs uncoated, $P=.005$ ), $177 \pm 41$ $\mu \mathrm{m}^{2} / \mu$ for fibrin-coated grafts (significant vs uncoated, $P=$ .012 ), and $131 \pm 39 \mu \mathrm{m}^{2} / \mu$ for uncoated grafts (Table 2 ). The incorporation of exogenous VEGF into fibrin tended to result in enhanced thickening compared with fibrin alone; however, this effect was not significant. In all study groups, wide areas of the neointima were lined at the luminal surface with CD31positive endothelial cells (Figure 2). Endothelialization of VEGF-fibrin-coated ePTFE grafts $(90 \% \pm 3 \%)$ was slightly, yet insignificantly, enhanced versus fibrin-coated $(82 \% \pm 4 \%)$ or uncoated $(80 \% \pm 4 \%)$ grafts (Table 2). CD31-stainings showed neointima to be essentially free of capillaries (Table 3; Figure 2). However, there was a high number of capillaries present in the adventitia. Further, staining for elastin fibers in the graft wall was negative (not shown). Examination of graft

TABLE 3. Capillary and macrophage counts in neointima and adventitia in coated and uncoated expanded polytetrafluoroethylene grafts at the one-month experimental end point

\begin{tabular}{lrcrc}
\hline & Uncoated & Fibrin & VEGF-fibrin & Kruskal-Wallis test \\
\hline Macrophage count in intima & $25 \pm 1.5$ & $19 \pm 3.5$ & $22 \pm 2.5$ & 0.981 \\
Capillary count in intima & $2.7 \pm 1.5$ & $3.2 \pm 1.1$ & $7.7 \pm 3.8$ & 0.542 \\
Capillary count in adventitia & $97.0 \pm 2.0$ & $104.7 \pm 11.8$ & $120.2 \pm 16.3$ & 0.368
\end{tabular}

VEGF, Vascular endothelial growth factor. Four grafts of each study group were examined. There was no significant difference between the study groups. 
surface ultrastructure by SEM (Figure 2) showed most parts lined by densely grown endothelial cells aligned in the direction of flow; sites of bare ePTFE surface were occasionally observed in uncoated grafts. VEGF and fibrin could act as chemoattractant and adhesion substrate for infiltrating monocytes, respectively, which in turn could activate smooth muscle cells by their secretion of cytokines and growth factors. However, our determination by MAC staining showed few macrophages in the neointima and no difference between the study groups (Table 3 ).

\section{Discussion}

The principal findings of this study were that impregnation of ePTFE graft surface with a slow-release fibrin coating for VEGF added little to the endothelialization rate but produced effects deleterious to graft healing beyond that seen in uncoated grafts: (1) increased angiographic narrowing at the proximal anastomosis and (2) increased neointimal thickening, especially when VEGF was present. Although the specific mechanisms underlying these adverse effects are not clear, the untoward role of VEGF deserves attention because it may be relevant for approaches to endothelial vessel regeneration after vessel injury in general.

Experimental studies of acute intraluminal arterial injury have led to the notion that the degree of reendothelialization inversely correlates with the thickness of the neointima. Exogenous VEGF activities, delivered as protein or gene, showed positive results for arterial healing through its acceleration of reendothelialization and attenuation of vascular smooth muscle cells after experimentally induced endothelial injury. ${ }^{17-19}$ Therefore, we have looked at VEGF-releasing substrate coatings to promote endothelial growth without provoking smooth muscle cell proliferation on prosthetic graft surfaces. In our experimental model, this strategy showed little effect for enhancing endothelial coverage over the synthetic graft surface, at least at the 1-month time point. This modest effect of exogenous VEGF for endothelial growth may be specific for this experimental model or the dosage of VEGF. It is also possible that VEGF activity per se may not be as important for endothelialization as assumed. In support for this notion, blockade of endogenous VEGF signaling after balloon-induced endothelial denudation did not impair endothelial regeneration. ${ }^{20}$

Impregnation with fibrin alone enhanced neointimal growth beyond that measured in uncoated grafts. Fibrin matrix in the form of the clinically approved plasma cryoprecipitate "fibrin glue" has been successfully used for ePTFE graft treatment in clinical ex vivo endothelialization approaches with mass-cultured autologous endothelial cells, ${ }^{21}$ as well as in preclinical in vivo endothelialization approaches. ${ }^{6}$ Work by Zarge and colleagues ${ }^{22}$ showed ePTFE grafts precoated with fibrin glue to be less prone to platelet deposition compared with whole blood-preclotted ePTFE. Potentially, the neointi- mal thickening response observed in our experiments could have been triggered at the early implantation stage through fibrin engagement of platelets or inflammatory cells, such as leukocytes or monocytes, through integrins $\alpha_{\mathrm{II}} \beta_{3}$ and $\alpha_{\mathrm{M}} \beta_{2}$, respectively. ${ }^{23}$ Platelets and monocytes secrete multiple factors, for example, platelet-derived growth factor, that activate smooth muscle cell. ${ }^{20}$ Our inspection by SEM revealed increased thrombus formation on fibrin-coated ePTFE grafts compared with uncoated specimen during a 30-minute perfusion period in the arteriovenous shunt test (Figure 1, B). The thrombin component used to form the fibrin coating on the ePTFE surface could activate platelets. Although the fibrinimpregnated grafts were washed before implantation, formally, we cannot exclude that early thrombus formation observed during shunt perfusion resulted from residual thrombin on fibrin-coated ePTFE grafts. At the 1-month experimental end point, the fibrin coatings were found completely remodeled into neointima, and approximately $80 \%$ to $90 \%$ of the ePTFE graft luminal surfaces were covered with endothelium (Table 2), without signs of thrombus (Figure 2).

Incorporation of VEGF into fibrin tended to further accentuate neointimal thickening. A dual effect of VEGF for enhancing the endothelialization rate of ePTFE grafts, but at the same time neointimal hyperplasia, was recently found in a rat abdominal artery interposition model. ${ }^{11}$ This indicates a general, relevant phenomenon of VEGF for neointimal thickening during synthetic graft healing. Notably, the experimental systems of both studies differed in many details, that is, in the animal model (pig vs rat), surgical location (carotid vs abdominal artery), graft diameter/length $(5 \mathrm{~cm} / 4$ $\mathrm{mm}$ vs $1 \mathrm{~cm} / 2 \mathrm{~mm}$ ), coating material (clinical relevant fibrin matrix vs experimental growth factor-reduced Matrigel [BD Biosciences, Franklin Lakes, NJ]), mechanisms of VEGF release (cell controlled vs passive release), and data acquisition (angiography and histology vs histology alone). From the literature, the contribution of VEGF to vessel wall healing after arterial injury has remained unclear and controversial. ${ }^{24}$ Accumulating evidence suggests that the overall effect of VEGF signaling during vessel wall healing may not be exclusively inhibitory for vascular smooth muscle cell growth as commonly assumed. Studies of arterial healing after experimental injury have indicated that exuberant smooth muscle growth could be mediated by direct activation of VEGF of smooth muscle cell migration ${ }^{25-27}$ or indirectly through VEGF-mediated vessel wall angiogene$\operatorname{sis}^{27}$ and recruitment of inflammatory cells such as monocytes. ${ }^{20}$ Our graft histology at 1 month showed few capillaries in the neointima and counts of MAC-positive cells to be low and indifferent between study groups. This suggests that neoangiogenesis and monocytes were unlikely causes for driving smooth muscle cell growth in this system in the later experimental phase; however, we cannot exclude those effects in the early phases of the experiment. 
Although our study in pigs found high spontaneous endothelial coverage of approximately $80 \%$ in bare and fibrincoated ePTFE grafts, and insignificant increase in the condition in which VEGF was present, bare ePTFE grafts in the rat model by Randone and colleagues ${ }^{11}$ exhibited a low spontaneous endothelial coverage of approximately 20\%, which was substantially increased to approximately $35 \%$ and $50 \%$ on coating with Matrigel alone or Matrigel plus VEGF, respectively. This shows great biological disparity between species in their capacities to spontaneously endothelialize synthetic grafts that can only be determined through the experiment.

Anastomotic ingrowth constitutes the most likely origin of endothelial and smooth muscle cells forming the neointima on our fibrin-impregnated ePTFE. Possibly, bone marrowderived circulating progenitor cells could also contribute to neointima hyperplasia by giving rise to smooth muscle cells as after arterial injury. ${ }^{28}$ Although the chemokine properties of VEGF for mobilizing endothelial progenitor cells are well established, ${ }^{29}$ a similar effect of VEGF for recruiting progenitors of smooth muscle cells is yet unknown.

The authors thank Stephanie Zimmerli, Sylvie Roulet, Manual Costa, Jean-Luc Munier, and Myriam Vitali for assistance during surgery; Unn Lutzen, Catherine Biton, Marie Claude Reymond, and Professor Ivo Krejci for their expertise in morphology and microscopy; Dr Nadia Popova for the postoperative ultrasound examinations; Dr Klaus Marquart, Dr Urs Ziegler, and Professor Groscurth from the University of Zurich for expert help with electron microscopy and histology.

\section{References}

1. Clowes AW. Improving the interface between biomaterials and the blood. The gene therapy approach. Circulation. 1996;93:1319-20.

2. Walpoth BH, Rogulenko R, Tikhvinskaia E, Gogolewski S, Schaffner $\mathrm{T}$, Hess OM, et al. Improvement of patency rate in heparin-coated small synthetic vascular grafts. Circulation. 1998;98:II319-23; discussion III324.

3. Meinhart JG, Deutsch M, Fischlein T, Howanietz N, Froschl A, Zilla P. Clinical autologous in vitro endothelialization of 153 infrainguinal ePTFE grafts. Ann Thorac Surg. 2001;71:S327-31.

4. Kidd KR, Patula VB, Williams SK. Accelerated endothelialization of interpositional 1-mm vascular grafts. J Surg Res. 2003;113:234-42.

5. Greisler HP, Klosak JJ, Dennis JW, Karesh SM, Ellinger J, Kim DU. Biomaterial pretreatment with ECGF to augment endothelial cell proliferation. J Vasc Surg. 1987;5:393-9.

6. Greisler HP, Cziperle DJ, Kim DU, Garfield JD, Petsikas D, Murchan $\mathrm{PM}$, et al. Enhanced endothelialization of expanded polytetrafluoroethylene grafts by fibroblast growth factor type 1 pretreatment. Surgery. 1992;112:244-54; discussion 254-5.

7. Wissink MJ, Beernink R, Poot AA, Engbers GH, Beugeling T, van Aken WG, et al. Improved endothelialization of vascular grafts by local release of growth factor from heparinized collagen matrices. J Control Release. 2000;64:103-14.

8. Hasson JE, Wiebe DH, Sharefkin JB, Abbott WM. Migration of adult human vascular endothelial cells: effect of extracellular matrix proteins. Surgery. 1986;100:384-91.

9. Bellon JM, Bujan J, Honduvilla NG, Hernando A, Navlet J. Endothelial cell seeding of polytetrafluoroethylene vascular prostheses coated with a fibroblastic matrix. Ann Vasc Surg. 1993;7:549-55.
10. Crombez M, Chevallier P, Gaudreault RC, Petitclerc E, Mantovani D, Laroche G. Improving arterial prosthesis neo-endothelialization: application of a proactive VEGF construct onto PTFE surfaces. Biomaterials. 2005;26:7402-9.

11. Randone B, Cavallaro G, Polistena A, Cucina A, Coluccia P, Graziano $\mathrm{P}$, et al. Dual role of VEGF in pretreated experimental ePTFE arterial grafts. J Surg Res. 2005;127:70-9.

12. Zisch AH, Schenk U, Schense JC, Sakiyama-Elbert SE, Hubbell JA. Covalently conjugated VEGF-fibrin matrices for endothelialization. J Control Release. 2001;72:101-13.

13. Ehrbar M, Metters A, Zammaretti P, Hubbell JA, Zisch AH. Endothelial cell proliferation and progenitor maturation by fibrin-bound VEGF variants with differential susceptibilities to local cellular activity. J Control Release. 2005;101:93-109.

14. Ehrbar M, Djonov VG, Schnell C, Tschanz SA, Martiny-Baron G, Schenk U, et al. Cell-demanded liberation of VEGF121 from fibrin implants induces local and controlled blood vessel growth. Circ Res. 2004; $94: 1124-32$.

15. Walpoth BH, Amonn A, Galdikas J, Ris HB, Schaffner T, Hoflin F, et al. Experimental assessment of thrombogenicity in vascular prostheses before and during prostaglandin E1 treatment. Eur J Vasc Surg. 1993; 7:493-9.

16. Bladin CF, Alexandrov AV, Murphy J, Maggisano R, Norris JW Carotid Stenosis Index. A new method of measuring internal carotid artery stenosis. Stroke. 1995;26:230-4.

17. Asahara T, Bauters C, Pastore C, Kearney M, Rossow S, Bunting S, et al. Local delivery of vascular endothelial growth factor accelerates reendothelialization and attenuates intimal hyperplasia in ballooninjured rat carotid artery. Circulation. 1995;91:2793-801.

18. Hutter R, Carrick FE, Valdiviezo C, Wolinsky C, Rudge JS, Wiegand $\mathrm{SJ}$, et al. Vascular endothelial growth factor regulates reendothelialization and neointima formation in a mouse model of arterial injury. Circulation. 2004;110:2430-5.

19. Walter DH, Cejna M, Diaz-Sandoval L, Willis S, Kirkwood L, Stratford PW, et al. Local gene transfer of phVEGF-2 plasmid by geneeluting stents: an alternative strategy for inhibition of restenosis Circulation. 2004;110:36-45.

20. Ohtani K, Egashira K, Hiasa K, Zhao Q, Kitamoto S, Ishibashi M, et al. Blockade of vascular endothelial growth factor suppresses experimental restenosis after intraluminal injury by inhibiting recruitment of monocyte lineage cells. Circulation. 2004;110:2444-52.

21. Zilla P, Deutsch M, Meinhart J, Puschmann R, Eberl T, Minar E, et al. Clinical in vitro endothelialization of femoropopliteal bypass grafts: an actuarial follow-up over three years. J Vasc Surg. 1994;19:540-8.

22. Zarge JI, Husak V, Huang P, Greisler HP. Fibrin glue containing fibroblast growth factor type 1 and heparin decreases platelet deposition. Am J Surg. 1997;174:188-92.

23. Flick MJ, Du X, Witte DP, Jirouskova M, Soloviev DA, Busuttil SJ, et al. Leukocyte engagement of fibrin(ogen) via the integrin receptor alphaMbeta2/Mac-1 is critical for host inflammatory response in vivo. J Clin Invest. 2004;113:1596-606.

24. Shiojima I, Walsh K. The role of vascular endothelial growth factor in restenosis: the controversy continues. Circulation. 2004;110:2283-6.

25. Ishida A, Murray J, Saito Y, Kanthou C, Benzakour O, Shibuya M, et al. Expression of vascular endothelial growth factor receptors in smooth muscle cells. J Cell Physiol. 2001;188:359-68.

26. Grosskreutz CL, Anand-Apte B, Duplaa C, Quinn TP, Terman BI, Zetter $\mathrm{B}$, et al. Vascular endothelial growth factor-induced migration of vascular smooth muscle cells in vitro. Microvasc Res. 1999;58:128-36.

27. Khurana R, Zhuang Z, Bhardwaj S, Murakami M, De Muinck E, Yla-Herttuala $S$, et al. Angiogenesis-dependent and independent phases of intimal hyperplasia. Circulation. 2004;110:2436-43.

28. Tanaka K, Sata M, Hirata Y, Nagai R. Diverse contribution of bone marrow cells to neointimal hyperplasia after mechanical vascular injuries. Circ Res. 2003;93:783-90.

29. Rafii S, Heissig B, Hattori K. Efficient mobilization and recruitment of marrow-derived endothelial and hematopoietic stem cells by adenoviral vectors expressing angiogenic factors. Gene Ther. 2002; 9:631-41. 